J. Management and Humanity Research

Vol. 3, 2020, 61-70

ISSN: 2582-7766 (online)

Published on 15 July 2020

www.researchmathsci.org

DOI: http://dx.doi.org/10.22457/jmhr.v03a06106

Journal of

Management and

Humanity Research

\title{
Research on the Influencing Factors of the Continuance Intention Online Education Platforms: Based on Expectation Confirmation Theory
}

\author{
Dong-shan Yang ${ }^{1 *}$ and Kun Jiang ${ }^{2}$ \\ ${ }^{1}$ School of Economics and Management, Chongqing University of Posts and \\ Telecommunications, Chongqing 400065, China \\ ${ }^{2}$ School of Economics and Management, Chongqing University of Posts and \\ Telecommunications, Chongqing 400065, China \\ *Corresponding Author: Dong-shan Yang. Email: 1654103631@qq.com \\ Address: No.2 Chongwen Road, Nan'an District, Chongqing 400065, China.
}

Received 9 June 2020; accepted 14 July 2020

\begin{abstract}
With the intensification of competition in the online education market, how to improve the satisfaction of online education platform users is an important practical issue. Based on the expectation confirmation theory, the article builds a conceptual model of the continuous use of online education platform users. Based on user survey data, the empirical results show that both perceived usefulness and confirmation have a significant positive impact on user satisfaction, and users' perceived usefulness and satisfaction both have a significant positive impact on users' Continuance Intention. Finally, according to the research results, it provides reference for the construction of online education platform.
\end{abstract}

Keywords: online education, expectation confirmation model, perceived usefulness, continuance intention

\section{Introduction}

From the service channels, education in my country can be divided into online education and offline education. Online education has the characteristics of strong pertinence, fragmented learning time, unlimited learning time and location, repeatable learning and high online interaction. Through the online education platform, users break through the constraints of traditional education time and space, and can choose the content they are interested in and useful for repeated learning anytime and anywhere. According to a report released by iResearch, the online education market reached 251.76 billion in 2018 , with a growth rate of $25.7 \%$. The market size is expected to reach 457.39 billion in 2021 . At the same time, the scale of online education users continues to increase, reaching 130 million people, a growth rate of $23.3 \%$, and the number of users is expected to reach 220 million in 2021. It can be seen that the market scale of the online education industry has huge potential and a large room for development, which has prompted more institutions to enter the online education industry. In the face of fierce market competition, how online education platform operators can improve user loyalty and stickiness has become 


\section{Dong-shan Yang and Kun Jiang}

an issue that must be considered for their sustainable development. Therefore, this article explores the factors that affect users' continued use of online education platforms.

\section{Theoretical basis and research hypothesis}

\subsection{Expectation confirmation theory}

In 1980, Oliver put forward the Expectancy Disconfirmation Theory (EDT). Before purchasing a product or service, users have certain expectations. After actually using the product or service, the user perceives the difference between the performance and expectations. The value is expected not to confirm.

The Expectation Confirmation Theory (ECT) is developed based on the Expectation Non-Confirmation Theory, which provides an important foundation for researching users' continuous use. Patterson et al. first applied the expectation confirmation theory to the field of information systems, and more and more scholars later applied the expectation confirmation theory to the field of information systems. Bhattacherjee (2001) proposed the Expectation Confirmation Model (ECM-ISC) by integrating TAM and ECM. The model includes four main variables: confirmation, perceived usefulness, satisfaction, and Continuance Intention. Bhattacherjee also found through research that the perceived usefulness and satisfaction of information system users have a significant positive impact on users' Continuance Intention, The user's desired confirmation degree affects the user's perceived usefulness and satisfaction, thereby affecting the user's Continuance Intention. After the expectation confirmation model was proposed, Larsen et al.'s research on mobile commerce, Tang and Chiang's research on blogs, Doong's research on knowledge sharing, and Kim's research on mobile data services all confirmed the effectiveness of the expectation confirmation model.

\subsection{Research hypothesis}

Bhattacherjee defines the expected degree of confirmation as the degree of confirmation between the expected and actual of the information system user before and after using the system, and the lower expectations and higher actual experience of the user will increase the user's expected degree of confirmation. Scholars in other fields of information systems have confirmed that the degree of confirmation has a positive impact on user satisfaction (Hwang \& Hsieh, 2007; Thong, Hong \& Tam, 2006; Hayashi et al., 2004; Lin, Wu \& Tsai, 2005). When a large number of scholars have a high degree of confirmation of other users' expectations based on the expectation confirmation model, it indicates that the user's expectations and user experience are met, which can improve the user's perceived usefulness of the platform and increase the user's satisfaction with the platform. Based on this, the following research hypotheses are proposed:

$\mathrm{H} 1$ : It is expected that the degree of confirmation will positively affect the satisfaction of users of online education platforms

Bhattacherjee (2001) verified the impact of confirmation on perceived usefulness in the expectation confirmation model. Genfu (2016) verified the positive effect of confirmation on perceived usefulness through research on MOOC users. Qian Ying (2015) also obtained a positive effect on perceived usefulness through research on online learning users. Lin, Wu \& Tsai (2005) and Hayashi et al. (2004) also verified the impact 
Research on the Influencing Factors of the Continuance Intention Online Education Platforms: Based on Expectation Confirmation Theory

of confirmation on perceived usefulness. Based on this, the following research hypotheses are proposed:

$\mathrm{H} 2$ : It is expected that the degree of confirmation will positively affect the perceived usefulness of users of online education platforms

In this article, perceived usefulness refers to the improvement of user learning efficiency and the degree of learning effect when users use online education platforms. Perceived usefulness not only affects the user's initial acceptance (Davis, 1989), but also has an important impact on user satisfaction and continued use intentions (Bhattacherjee, 2001). Liu Hong et al. (2014) verified the effect of perceived usefulness on satisfaction in the study of users' Continuance Intention video websites. Yang Tao's (2016) research on e-book users also verified the positive impact of perceived usefulness on satisfaction. If users' perceived usefulness of online education platforms is low, users' satisfaction with the platform will decrease. Based on this, the following research hypotheses are proposed:

H3: Perceived usefulness will positively affect user satisfaction of online education platforms

H4: Perceived usefulness will positively affect users' Continuance Intention online education platforms

In this article, the willingness to continue to use refers to the willingness of online education platform users to continue using the selected online education platform. The degree of Continuance Intention online education platform users reflects the level of user loyalty to the selected online education platform. Satisfaction is the user experience and overall evaluation after using the online education platform. A large number of scholars have confirmed that satisfaction has a positive effect on the willingness to continue use (Yang Genfu, 2016; Bhattacherjee, 2001; Qian Ying, 2015). Based on this, the following research hypotheses are proposed:

H5: Satisfaction will positively affect online education platform users' Continuance Intention

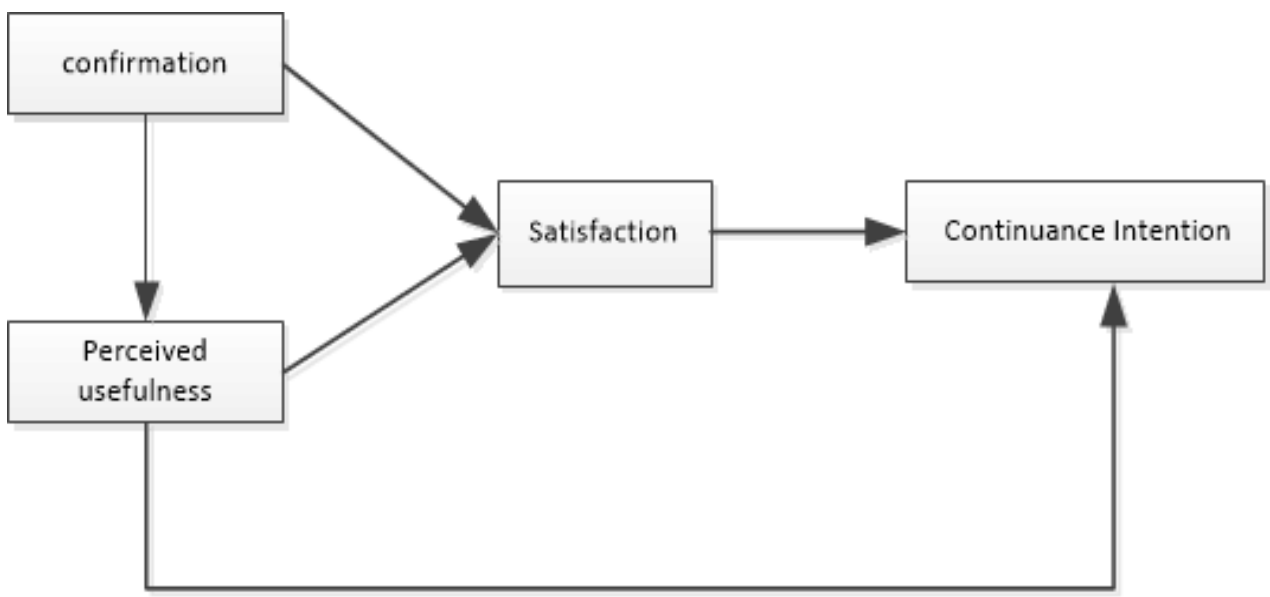

Figure 1: Expectation confirmation model 


\section{Dong-shan Yang and Kun Jiang}

Based on the theoretical model of expectation confirmation, this paper discusses the Continuance Intention online education platform users. When users perceive and use online education platforms, according to the expectation confirmation model, perceived usefulness and confirmation are important factors that affect satisfaction, which in turn have an effect on the willingness to continue to use. The expectation confirmation model is shown in Figure 1.

\section{Research design}

\subsection{Scale design}

The development of the questionnaire is based on the mature scale of the willingness to use information systems at home and abroad, and at the same time, the relevant research on online education platforms at home and abroad is referred to, and then the scale is appropriately modified. The questionnaire consists of two parts: the first part is the basic user information; the second part is the measurement of the factors affecting the continuous use behavior of online education platform users (Table 1). The questionnaire uses the Likert five-point scale method, 1 represents "strongly disagree", 2 represents "relatively disagree", 3 represents "unsure", 4 represents "relatively agree", and 5 represents "strongly agree".

Table 1: Measurement items and reference sources

\begin{tabular}{|c|c|c|}
\hline Variable & Measurement standard & Reference source \\
\hline \multirow[t]{3}{*}{ Confirmation } & $\begin{array}{l}\text { CF1 The experience of using the } \\
\text { online education platform is better } \\
\text { than I expected }\end{array}$ & \multirow[t]{3}{*}{$\begin{array}{l}\text { Bhattacherjee(2001) } \\
\text { Lee(2010) } \\
\text { De Lone \& Mc Lean(2003) }\end{array}$} \\
\hline & $\begin{array}{l}\text { CF2 The services and functions } \\
\text { provided by the online education } \\
\text { platform are better than I expected }\end{array}$ & \\
\hline & $\begin{array}{l}\text { CF3 Overall, my expectations of } \\
\text { using the online education platform } \\
\text { to learn are met }\end{array}$ & \\
\hline \multirow[t]{2}{*}{$\begin{array}{l}\text { Perceived } \\
\text { Usefulness }\end{array}$} & $\begin{array}{l}\text { PU1 Using online education } \\
\text { platform to study can improve my } \\
\text { learning effect }\end{array}$ & \multirow[t]{2}{*}{$\begin{array}{l}\text { Bhattacherjee(2001) } \\
\text { Venkatesh(1993) } \\
\text { Davis(1989) }\end{array}$} \\
\hline & $\begin{array}{l}\text { PU2 Using online education } \\
\text { platform to study can improve my } \\
\text { learning efficiency }\end{array}$ & \\
\hline \multirow[t]{3}{*}{ Satisfaction } & $\begin{array}{l}\text { SA1 I am satisfied with the } \\
\text { decision to use the online education } \\
\text { platform to learn }\end{array}$ & \multirow[t]{3}{*}{$\begin{array}{l}\text { Lee\&Lin ( 2005) } \\
\text { Yang et al ( 2005) } \\
\text { Wang\&Liao ( 2008) }\end{array}$} \\
\hline & $\begin{array}{l}\text { SA2 I am satisfied with the effect } \\
\text { of using the online education } \\
\text { platform to learn }\end{array}$ & \\
\hline & $\begin{array}{l}\text { SA3 I am satisfied with the } \\
\text { experience provided by the online } \\
\text { education platform }\end{array}$ & \\
\hline Continuance & CI1 I am willing to continue to use & Rca et al (2006) \\
\hline
\end{tabular}


Research on the Influencing Factors of the Continuance Intention Online

Education Platforms: Based on Expectation Confirmation Theory

\begin{tabular}{|l|l|l|}
\hline Intention & $\begin{array}{l}\text { the online education platform to } \\
\text { study }\end{array}$ & \multirow{2}{*}{ Hsu \& Chiu (2004) } \\
\cline { 2 - 3 } & $\begin{array}{l}\text { CI2 I am willing to use the online } \\
\text { education platform to study } \\
\text { regularly in the future }\end{array}$ & \\
\cline { 2 - 3 } & $\begin{array}{l}\text { CI3 I am willing to increase the } \\
\text { frequency of learning and using } \\
\text { online education platforms }\end{array}$ & \\
\hline
\end{tabular}

\subsection{Research sample}

In this study, users of online education platforms were selected as the research object. A total of 410 questionnaires were collected through the form of online questionnaires. Among the questionnaire samples (Table 2), there were 226 males, accounting for $55.12 \%$ of the total number, and 184 females accounting for the total number. $44.88 \%$ of the sample, the sample has a bachelor's degree or above, mostly students and corporate employees, and the frequency of using online education platforms is mostly at least once a week and above.

Table 2: Basic user characteristics table

\begin{tabular}{|l|l|l|l|}
\hline feature & distributed & $\begin{array}{l}\text { Number } \\
\text { of } \\
\text { people }\end{array}$ & proportion \\
\hline gender & male & 226 & $55.12 \%$ \\
& female & 184 & $44.88 \%$ \\
\hline Education & Bachelor degree or above & 90 & $21.95 \%$ \\
& Undergraduate & 200 & $48.78 \%$ \\
& Postgraduate & 81 & $19.76 \%$ \\
& Postgraduate and above & 39 & $9.51 \%$ \\
\hline Profession & Student & 198 & $48.29 \%$ \\
& Corporate employees & 140 & $34.15 \%$ \\
& Staff of institutions & 37 & $9.02 \%$ \\
& Government staff & 9 & $2.2 \%$ \\
& Freelancers & 16 & $3.9 \%$ \\
& Other occupations & 10 & $2.44 \%$ \\
\hline usage & Daily use & 85 & $20.73 \%$ \\
frequency & At least every three days & 130 & $31.71 \%$ \\
& At least once a week & 106 & $25.85 \%$ \\
& At least once every two & 26 & $6.34 \%$ \\
& weeks & 63 & $15.37 \%$ \\
& At least once a month & & \\
\hline
\end{tabular}




\section{Dong-shan Yang and Kun Jiang}

\subsection{Variable correlation analysis}

Variable descriptive statistics and correlation analysis are shown in the following table. All variables show significant correlation, and the survey data can be subjected to further regression analysis and hypothesis testing. The mean, standard deviation and correlation coefficient are shown in Table 3.

Table 3: Descriptive statistical analysis and Pearson correlation coefficient matrix

\begin{tabular}{|l|l|l|l|l|l|l|}
\hline variable & $\begin{array}{l}\text { average } \\
\text { value }\end{array}$ & $\begin{array}{l}\text { Standard } \\
\text { deviation }\end{array}$ & 1 & 2 & 3 & 4 \\
\hline 1.confirmation & 3.90 & 0.67 & 1 & & & \\
\hline 2.Perceived usefulness & 3.84 & 0.81 & $0.606^{* *}$ & 1 & & \\
\hline 3. Satisfaction & 3.85 & 0.63 & $0.665^{* *}$ & $0.623^{* *}$ & 1 & \\
\hline 4.Continuance Intention & 4.05 & 00.65 & $0.466^{* *}$ & $0.494^{* *}$ & $0.522^{* *}$ & 1 \\
\hline
\end{tabular}

Note: $*$ indicates the significance level $\mathrm{p}<0.1, * *$ indicates the significance level $\mathrm{p}<0.05$, $* * *$ indicates the significance level $\mathrm{p}<0.01$

\subsection{Reliability and validity analysis}

The reliability and validity of the questionnaire were tested by spss23.0. The Cronbach's $\alpha$ value of the entire questionnaire was 0.896 and the Cronbach's $\alpha$ value of each variable was above 0.610 (Table 4). The variables showed good internal consistency, So the reliability of the questionnaire is acceptable. The KMO value of this questionnaire is 0.896 , and the KMO value of each variable is greater than 0.5, indicating that the overall degree of interpretation is high, and the Bartlett sphere test value is significant at the level of 0.000 , so the principal component analysis is reasonable and the cumulative variance explanation is obtained. The rate is $67.444 \%$, and the factor loading value of each item is above 0.5 , indicating that the validity of the sample is good.

Table 4: Variable indicators and factor analysis results

\begin{tabular}{|c|c|c|c|}
\hline variable & Item & Cronbach' s $\alpha$ & $\begin{array}{l}\text { Factor } \\
\text { loading }\end{array}$ \\
\hline \multirow{3}{*}{ confirmation } & CF1 & \multirow{3}{*}{0.755} & 0.725 \\
\hline & $\mathrm{CF} 2$ & & 0.709 \\
\hline & CF3 & & 0.725 \\
\hline \multirow[t]{2}{*}{ Perceived usefulness } & PU1 & \multirow[t]{2}{*}{0.708} & 0.741 \\
\hline & PU2 & & 0.746 \\
\hline \multirow[t]{3}{*}{ Satisfaction } & SA1 & \multirow[t]{3}{*}{0.610} & 0.601 \\
\hline & SA2 & & 0.617 \\
\hline & SA3 & & 0.583 \\
\hline \multirow{3}{*}{ Continuance intention } & CI1 & \multirow[t]{3}{*}{0.644} & 0.664 \\
\hline & CI2 & & 0.602 \\
\hline & $\mathrm{CI} 3$ & & 0.594 \\
\hline
\end{tabular}




\section{Research on the Influencing Factors of the Continuance Intention Online}

Education Platforms: Based on Expectation Confirmation Theory

\subsection{Model checking}

The purpose of model fit detection is to measure the degree of conformity between the hypothetical model and the actual observation data. This research is tested by absolute adaptation index, value-added adaptation index and simple adaptation index. It can be seen from Table 5 that overall, the research model has a good degree of adaptation.

Table 5: Model adaptation analysis

\begin{tabular}{|l|l|l|l|l|l|l|}
\hline $\begin{array}{l}\text { Fitting } \\
\text { index }\end{array}$ & X2/df & GFI & NFI & CFI & RMR & RMSEA \\
\hline result & 1.656 & 0.953 & 0.929 & 0.970 & 0.030 & 0.040 \\
\hline $\begin{array}{l}\text { evaluation } \\
\text { standard }\end{array}$ & $<5$ & $>0.9$ & $>0.9$ & $>0.9$ & $<0.05$ & $<0.05$ \\
\hline
\end{tabular}

\subsection{Hypothesis verification}

As shown in Figure 2, the degree of user's confirmation of online education platform significantly positively affects their satisfaction with online education platform ( $\beta=$ $0.622, \mathrm{P}<0.001$ ), and the research hypothesis H1 is supported. The degree of user's expectation and confirmation of online education platforms significantly positively affects their perceived usefulness of online education platforms $(\beta=0.367, \mathrm{P}<0.001)$, and the research hypothesis $\mathrm{H} 2$ is supported. Users' perceived usefulness of online education platforms has a significant positive impact on their satisfaction with online education platforms $(\beta=0.482, \mathrm{P}<0.001)$. Research hypothesis $\mathrm{H} 3$ is supported. Users' perceived usefulness of online education platforms has a significant positive impact on their Continuance Intention online education platforms $(\beta=0.393, \mathrm{P}<0.001)$. Research hypothesis $\mathrm{H} 4$ is supported. User satisfaction with online education platforms significantly positively affects their Continuance Intention online education platforms ( $\beta 11=0.568, \mathrm{P}<0.001)$, and the research hypothesis $\mathrm{H} 5$ is supported. The five research hypotheses derived from the expectation confirmation model are all supported.

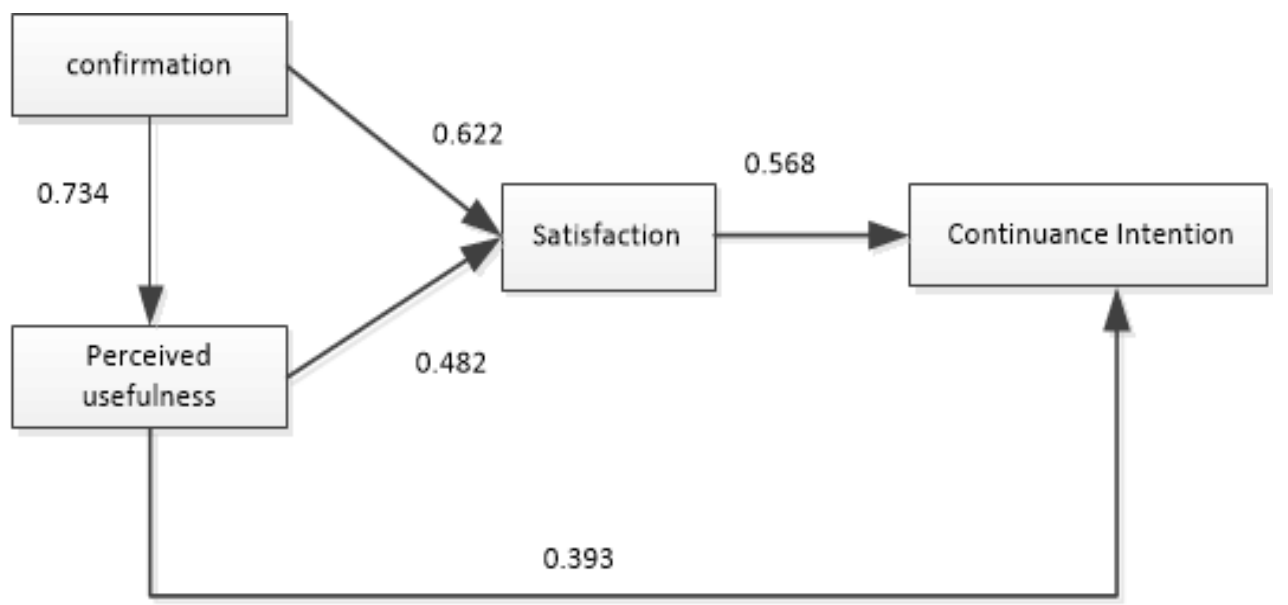

Figure 2: Regression analysis results of online education platform user satisfaction 


\section{Dong-shan Yang and Kun Jiang}

\section{Conclusions and Suggestions}

\subsection{Conclusion}

Based on the theory of expectation confirmation, this paper combines the characteristics of online education platform to construct an expectation confirmation model. The results show that: (1) The user satisfaction formed by users of online education platform during the use of the platform is an important factor affecting their continued use of the platform; (2) The perceived usefulness of online education platform during use will continue for users The intention to use has a positive impact; (3) The perceived usefulness of the online education platform during the use process will affect satisfaction, and the degree of confirmation is expected to significantly affect the perceived usefulness and satisfaction of users.

\subsection{Suggestions}

(1) Make the online education platform meet user expectations

The degree of confirmation of expectations of online education platform users has a significant positive impact on perceived usefulness and satisfaction. Online education platforms should carry out actual publicity during publicity instead of exaggerated publicity, which leads to a large gap after users use it.

(2) Make users feel the usefulness of online education platforms

Perceived usefulness has a significant positive impact on the satisfaction of online education platform users. The more useful the online education platform is, the higher the user satisfaction. Therefore, online education platforms should highlight their advantages, functions, and content quality, so that users can feel the usefulness of online education platforms, and thereby improve user satisfaction.

(3) Make users feel the platform's good service quality

The better the service quality of the platform, the higher the user's expectation of the online education platform and the more useful it can be felt. Therefore, online education platforms should improve the service quality of their customer service and provide professional training to them so that they can help users solve problems better, faster and more professionally.

(4) Make users feel the quality of high-quality courses

Online education platforms can provide users with some value-added or free services in the process of user use, and improve user satisfaction. At the same time, online education platforms can provide a platform for teachers, users, and users to communicate with each other. Users' questions can be answered in a timely manner, so that users can feel the usefulness of the online education platform and improve user confirmation.

\section{REFERENCES}

1. Y.Qian, Research on the influencing factors of online learning users' continued use behavior-based on the perspective of social network environment and academic positioning, Modern Information, 35(3) (2015) 50-56.

2. G.Yang, Research on influencing factors of continuous use behavior of MOOC users, Open Education Research, 22(1) (2016) 100-111. 
Research on the Influencing Factors of the Continuance Intention Online Education Platforms: Based on Expectation Confirmation Theory

3. R.L.Oliver, A cognitive model of the antecedents and consequences of satisfaction decisions, Journal of Marketing Research, 17(4) (1980) 460-469.

4. P.G.Patterson, L.W.Johnson and R.A.Spreng, Modeling the determinants of customer satisfaction for business-to-business professional services, Journal of the Academy of Marketing Science, 25(1) (1996) 4-17.

5. A.Bhattacherjee, Understanding information systems continuance: an expectationconfirmation model, MIS Quarterly, 25(3) (2001) 351-370.

6. T.J.Larsen, A.M.Søreb $\varnothing$ and $\varnothing . S \varnothing r e b \emptyset$, The role of task-technology fit as users' motivation to continue information system use, Computers in Human Behavior, 25(3) (2009) 778-784.

7. J.E.Tang and C.Chiang, Integrating experiential value of blog use into the expectation-confirmation theory model, Social Behavior and Personality: an International Journal, 38(10) (2010) 1377-1389.

8. H.S.Doong and H.Lai, Exploring usage continuance of e-negotiation systems: expectation and disconfirmation approach, Group Decision and Negotiation, 17(2) (2008) 111-126.

9. B.Kim, An empirical investigation of mobile data service continuance: Incorporating the theory of planned behavior into the expectation-confirmation model, Expert Systems with Applications, 37(10) (2010) 7033-7039.

10. F.D.Davis, Perceived usefulness, perceived ease of use, and user acceptance of information technology, MIS Quarterly, 13(3) (1989) 319-340.

11. M.C.Lee, Explaining and predicting users' continuance intention toward e-learning: An extension of the expectation-confirmation model, Computers \& Education, 54(2) (2010) 506-516.

12. R.Venkatesh, Computation of Elastic Moduli and Dispersion in (s-d) Interactive Atomic Liquids. The Example of Liquid Pt and Pd Metals, Physica Status Solidi (b), 176(1) (1993) 91-99.

13. G.G.Lee and H.F.Lin, Customer perceptions of e - service quality in online shopping, International Journal of Retail \& Distribution Management, 33(2) (2005) 161-176.

14. Z.Yang, S.Cai and Z.Zhou, Development and validation of an instrument to measure user perceived service quality of information presenting web portals, Information \& Management, 42(4) (2005) 575-589.

15. Y.S.Wang and Y.W.Liao, Assessing eGovernment systems success: A validation of the DeLone and McLean model of information systems success, Government Information Quarterly, 25(4) (2008) 717-733.

16. J.Y.L.Thong, S.J.Hong and K.Y.Tam, The effects of post-adoption beliefs on the expectation-confirmation model for information technology continuance, International Journal of Human-Computer Studies, 64(9) (2006) 799-810.

17. M.C.Hung, H.G.Hwang and T.C.Hsieh, An exploratory study on the continuance of mobile commerce: an extended expectation-confirmation model of information system use, International Journal of Mobile Communications, 5(4) (2007) 409-422.

18. A.Hayashi, C.Chen and T.Ryan, The role of social presence and moderating role of computer self efficacy in predicting the continuance usage of e-learning systems, Journal of Information Systems Education, 15(2) (2020) 5. 


\section{Dong-shan Yang and Kun Jiang}

19. C.S.Lin, S.Wu and R.J.Tsai, Integrating perceived playfulness into expectationconfirmation model for web portal context, Information \& Management, 42(5) (2005) 683-693.

20. H.Liu, L.Pei and J.Sun, An Empirical Analysis of Continuous Use of Video Website Users Based on the Expectation Confirmation Model, Library, Information, and Knowledge, 3 (2014) 94-103.

21. T.Yang, Research on the continuous use behavior of e-book users: an extension of the expectation confirmation model, Research in Library Science, 22 (2016) 76$83+68$.

22. J.C.Roca, C.M.Chiu and F.J.Martínez, Understanding e-learning continuance intention: An extension of the Technology Acceptance Model, International Journal of Human-Computer Studies, 64(8) (2006) 683-696.

23. M.H.Hsu and C.M.Chiu, Predicting electronic service continuance with a decomposed theory of planned behavior, Behaviour \& Information Technology, 23(5) (2004) 359-373. 